\title{
The syndrome of congenital facial palsy and unilateral anotia
}

\author{
Aamir Jalal Al Mosawi ${ }^{1,2 *}$ \\ ${ }^{1}$ Advisor in Pediatrics and Pediatric Psychiatry, Children Teaching Hospital of Baghdad Medical City, Iraq \\ ${ }^{2} \mathrm{Head}$, Iraq Headquarter of Copernicus Scientists International Panel, Baghdad, Iraq
}

\begin{abstract}
The syndrome of unilateral anotia, and ipsilateral facial palsy is one of the extremely rare manifestations of genetic abnormalities.

The occurrence of microtia/anotia syndrome in association with congenital facial palsy has been reported in association with teratogenic effect of thalidomide and retinoic acid, well-Known syndromes such as Berry Treacher Collins and Goldenhar, and poorly characterized cardiofacial syndrome or syndromes including the cases of Matthies, Pearl, Hall, Bretton Chappuis and Engel, and Girisha and Phadke.

There have been very few reports of the occurrence of microtia/anotia syndrome in association with congenital facial palsy without other congenital cardiac defects or other congenital abnormalities. These reports include the reports of Parkash and colleagues, Gathwala and colleagues and Mahale, et al.

The aim of this paper is to describe the extremely rare occurrence of the syndrome of congenital ipsilateral facial palsy and unilateral anotia in an Iraqi infant.

This Iraqi patient most probably represents the fourth patient with the syndrome of microtia/anotia syndrome and congenital facial palsy without other abnormalities.
\end{abstract}

\section{Introduction}

Anotia (No ear) is a rare congenital malformation of the complete absence of the pinna of the ear, and narrowing or absence of the ear canal. Microtia is a rare congenital malformation with the presence of a small part of the pinna. The two conditions anotia and microtia may occur unilaterally or bilaterally, and they result in conductive hearing loss. Isolated anotia and microtia were thought to have a genetic basis. Anotia/microtia occurs when tissues associated with the formation of the auricle do not develop [1,2].

The association of ear malformation and cranial nerve palsies was originally reported to occur in thalidomide children. Matthies reported the occurrence of anotia and facial paralysis facial paralysis in association with cardiac defect in non-thalidomide children [2-4].

The occurrence of microtia/anotia syndrome in association with congenital facial palsy has also been reported in association with teratogenic effect retinoic acid [1].

Well-Known syndromes associated with microtia/anotia and congenital facial palsy include Berry Treacher Collins and Goldenhar [1,2].

The syndrome of complete unilateral anotia and ipsilateral facial palsy is one of the extremely rare manifestations of genetic abnormalities.

The aim of this paper is to describe the extremely rare occurrence of the syndrome of congenital facial palsy and ipsilateral anotia in an Iraqi infant.

\section{Case report}

Y.S was first seen at the age of 45 days because unilateral anotia occurring in association with ipsilateral congenital facial palsy. The parents were relatives and had other three normal children. A cousin of the patient had isolated congenital unilateral facial palsy and she was doing well at sixth grade primary school. The facial paralysis in the cousin of the patient was not attributed to traumatic delivery or birth asphyxia and didn't show obvious improvement with time.

Y.S had complete absence of the right ear, while her left ear was normal (Figure 1). She also had right facial palsy (Figure 2). When the patient was sleeping, both eyes were closed. When she was awake and calm, there was loss of the nasolabial fold on the right side, but when she became more vigilant, the right eye was more widely open than the left. When the patient cried vigorously, the was obviously paralysis of the right side with no contraction of the right side of the face, absence of the nasolabial fold and incomplete closure of the right eye confirming lower motor neuron lesion of the right facial nerve (Figure 2) and poorly characterized cardiofacial syndrome or syndromes including the cases Girisha and Phadke.

\section{Discussion}

The occurrence of microtia/anotia syndrome in association with congenital facial palsy has been reported in association with poorly characterized cardiofacial syndrome or syndromes including the cases of Matthies [4] , Pearl [5], Hall [6], Bretton Chappuis and Engel [7], and Girisha and Phadke [8].

${ }^{\star}$ Correspondence to: Aamir Jalal Al Mosawi, Advisor in Pediatrics and Pediatric Psychiatry, Children Teaching Hospital of Baghdad Medical City, Iraq, E-mail: almosawiAJ@yahoo.com

Key words: anotia, facial palsy, congenital, Iraq

Received: October 31, 2019; Accepted: November 11, 2019; Published: November 14, 2019 


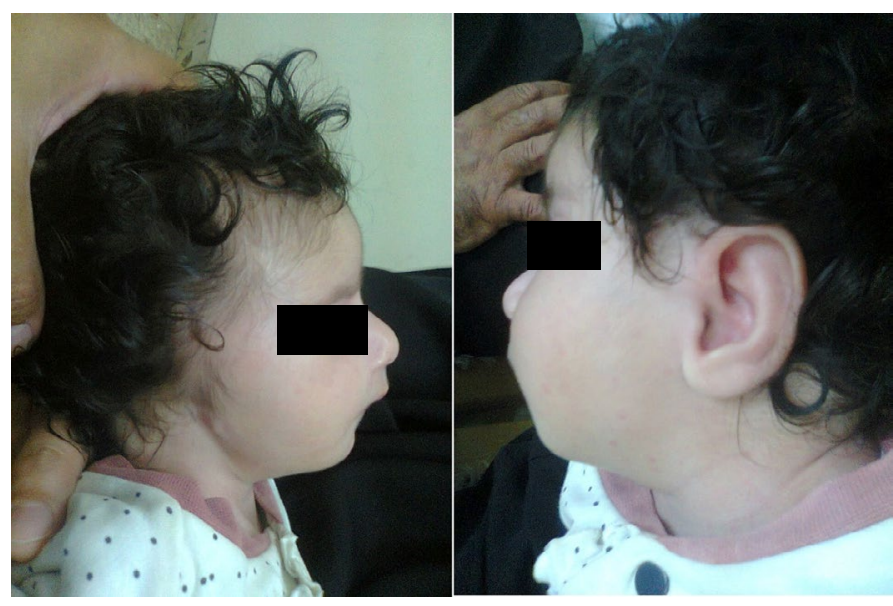

Figure 1. The patient had complete absence of the right ear, while her left ear was normal

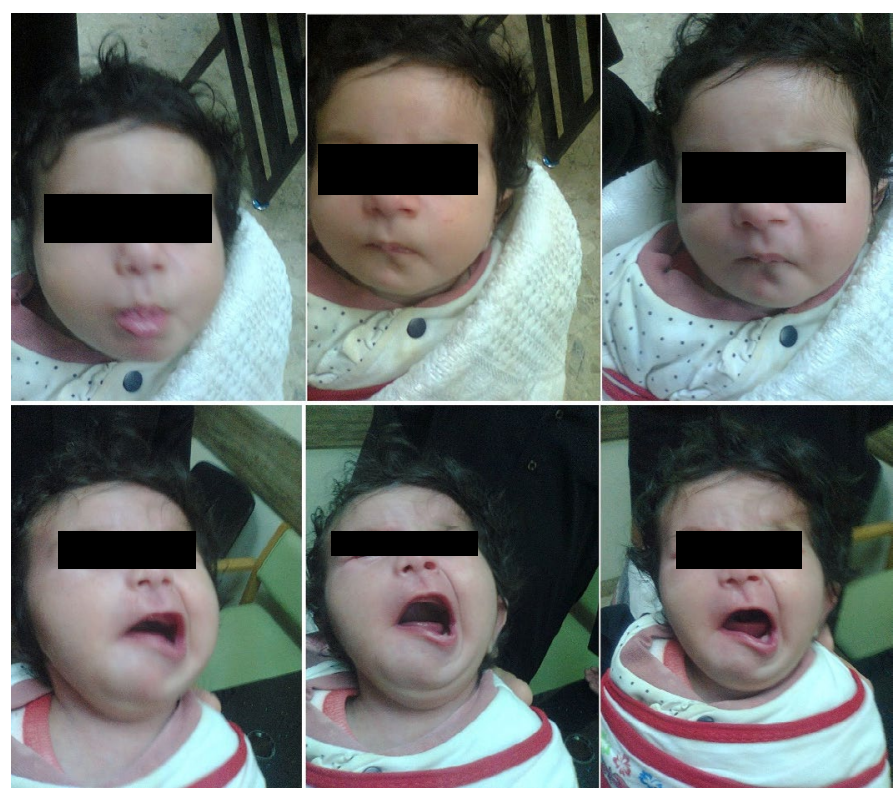

Figure 2. The girl also had right facial palsy Brain CT-scan (Axial and 3D native sections showed normal findings
There have been very few reports of the occurrence of microtia/ anotia syndrome in association with congenital facial palsy without congenital cardiac defects or other congenital abnormalities. These reports include the reports of Parkash and colleagues [9], Gathwala and colleagues, [10], Mahale, et al. [11].

Therefore, this Iraqi patient represents the fourth patient with the syndrome of microtia/anotia syndrome and congenital facial palsy without other abnormalities.

\section{Acknowledgement}

The author would to express his gratitude for the parents of the patient who accepted publishing her photos.

\section{References}

1. Al-Mosawi AJ (2016) Berry-Treacher Collins syndrome. LAP Lambert Academic Publishing.

2. Al-Mosawi AJ (2018) The syndrome of absent ear and congenital facial palsy. (1st Edn) Saarbrücken; LAP Lambert Academic Publishing.

3. Davignon M, Barr B (1964) Ear Abnormalities And Cranial Nerve Palsies In Thalidomide Children. Arch Otolaryngol 80: 136-140. [Crossref]

4. Matthies F (1966) The triad of anotia, facial paralysis, and cardiac anomaly not due to thalidomide. JAMA 195: 695-696. [Crossref]

5. Pearl W (1984) Syndrome of anotia, facial paralysis, and congenital heart disease. $J$ Pediatr 105: 441-442.

6. Hall BD (1985) Anotia, facial paralysis, and heart disease. J Pediatr 106: 532. [Crossref]

7. Bretton Chappuis B, Engel E (1989) Anotia, facial paralysis, heart abnormalities: specific triad or variant of Goldenhar syndrome? Ann Genet 32: 52-54.

8. Girisha KM, Phadke SR (2005) Anotia and facial palsy: unusual features of cardiofacial syndrome. Indian J Pediatr 72: 525-526.

9. Parkash H, Grewal MS, Sidhu SS (1982) Microtia-atresia with unilateral facial palsy. Indian Pediatr 19: 445-448.

10. Gathwala G, Singh J, Dalal P (2013) Congenital facial palsy with bilateral anotia Indian J Clin Pract 23: 628-634.

11. Mahale RR, Mehta A, John AA, Buddaraju K, Shankar AK, et al. (2016) Newborn with congenital facial palsy and bilateral anotia/atresia of external auditory canal: Rare occurrence. J Pediatr Neurosci 11: 271-273.

Copyright: C2019 AL-Mosawi AJ. This is an open-access article distributed under the terms of the Creative Commons Attribution License, which permits unrestricted use, distribution, and reproduction in any medium, provided the original author and source are credited. 